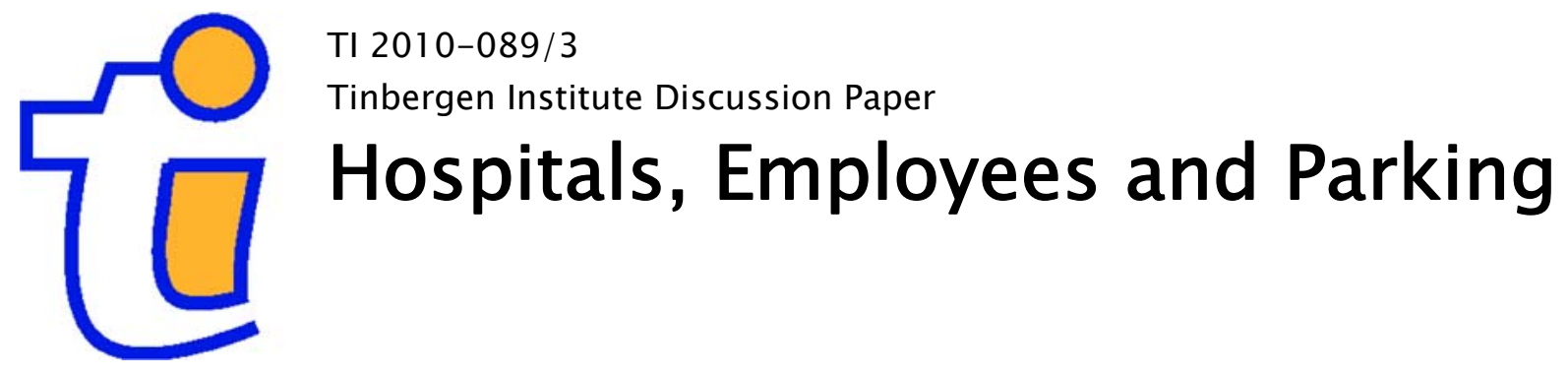

Jos van Ommeren*

Giovanni Russo

VU University Amsterdam

* Tinbergen Institute 


\section{Tinbergen Institute}

The Tinbergen Institute is the institute for economic research of the Erasmus Universiteit Rotterdam, Universiteit van Amsterdam, and Vrije Universiteit Amsterdam.

Tinbergen Institute Amsterdam

Roetersstraat 31

1018 WB Amsterdam

The Netherlands

Tel.: +31(0)205513500

Fax: $+31(0) 205513555$

Tinbergen Institute Rotterdam

Burg. Oudlaan 50

3062 PA Rotterdam

The Netherlands

Tel.: + $31(0) 104088900$

Fax: $+31(0) 104089031$

Most TI discussion papers can be downloaded at http://www.tinbergen.nl. 


\title{
Hospitals, employees and parking
}

\author{
Jos van Ommeren
}

Giovanni Russo

$8 / 31 / 2010$

Abstract. We study the employees' demand for hospital parking. We estimate the effect of the employees' parking price on demand using a difference-in-differences methodology. The deadweight loss generated by non-optimal pricing of parking is at least $9 \%$ of the hospitals' parking resource costs.

VU University, FEWEB, De Boelelaan, 1081 HV Amsterdam, the Netherlands; Email: jommeren@feweb.vu.nl Jos van Ommeren would like to thank Netherlands Organisation for Scientific Research (NWO) for funding. We would like to thank Richard Arnott for comments, Marcel Hoogzaad for valuable assistance, the Bronovo hospital for providing data and Daan van Egeraat for advice. 


\section{Introduction}

Parking policies at hospitals for patients, visitors and workers is a hotly debated issue, at least in the popular press, ${ }^{1}$ but hospital parking has received little or no attention in the (health) economic literature. ${ }^{2}$ Hospitals usually charge workers a price for the use of parking that is much lower than its resource cost (or the price paid by patients/visitors). Parking space is rather costly to hospitals (National Parking Association 2009) ${ }^{3}$, but at the same time, the supply of (free) parking space is considered to be an important non-wage job characteristic for hospital workers as hospitals compete on the provision of (free) parking to workers (Noether, 1988; Thomson, 1994).

In the current paper, we focus on the consequences of not charging the costs of full parking at a hospital in the Netherlands. We estimate the effect of the price of parking on hospital workers' demand for parking. This allows us to determine the deadweight loss from not charging the full price. This loss is, at least partially, induced by taxation, because the provision of parking is not taxed as income, which stimulates hospitals to offer parking below its cost price, or even free, and to increase the supply of parking. ${ }^{4}$ To determine the price effect on parking demand, we focus on a hospital that varied the parking pricing regime in several ways. In particular, it varied the parking price over the days of the week, after a period when it varied only with commuting distance. To vary price per day is rather unique (we are not aware of any other organisation employing this

\footnotetext{
${ }^{1}$ This is especially so in the UK popular media. A recent poll has shown that parking fees at hospitals are regarded as the "biggest injustice".

${ }^{2}$ Parking policies at hospitals differ from organisations in other industries, as a substantial proportion of hospitals charge workers for parking (National Parking Association 2009). This is in contrast to most other industries where charging is uncommon (see Small and Verhoef, 2007). Charging hospital workers for parking is a relatively new phenomenon. In the US, it is common to have minimum parking requirements for hospitals (Shoup, 2005). This is not the case in the Netherlands, and, as far as we are aware, not in any other European country.

${ }^{3}$ For example, the construction costs of a multi-storey parking, excluding the cost of land or of any special foundations are about $€ 10,000$ per space (Parking Consultants Ltd. 2010).

${ }^{4}$ According to theory, when parking supply is fully flexible and wages can be fully adjusted, then parking will be offered for free.
} 
practice), and in line with economic theory to deal with variation in demand. ${ }^{5} \mathrm{~A}$ relevant question is then to what extent daily variation in pricing increases the efficiency of the use of parking space. It is this latter characteristic that receives special attention in the current paper.

Hospitals operate on a 24-hours a day basis, hence within-day parking variation in demand is related to the timing of nurses' and doctors' shifts (one peak between 7 am and 8 am and another one between 2 and $3 \mathrm{pm}$ ), the arrival of administrative staff (at around 9 am) and of patients scheduled for treatment. ${ }^{6}$ Parking demand on weekdays far exceeds the demand on weekends, but, as we will document later on, there also is quite some variation between weekdays, a characteristic which is ignored in the literature (e.g. Arnott et al., 1991).

The hospitals' parking resource costs are hardly related to the use of the parking lot. These costs are not only fixed, they are also joint (as each parking space may be used by more than one individual). In line with principles already discussed by Pigou (1912), the optimal parking price to be paid by workers, which refers here to the price that induces efficient use of parking space, varies then per day such that the workers' marginal willingness to pay for parking per week equals the hospitals' parking costs over this period. ${ }^{7}$ The optimal parking price is zero on days with excess supply - the slack days - and positive on the remaining days - the peak days. ${ }^{8}$ We estimate the deadweight loss of not using the optimal parking price.

The structure of the paper is the following: Section 2 contains the data description. Section 3 presents the empirical results. Section 4 offers concluding remarks.

\footnotetext{
${ }^{5}$ Importantly, for the current paper, it is also useful to properly identify the causal effect of pricing on parking demand by hospital workers.

${ }^{6}$ Visitors are less relevant here because this is a relatively small group who predominantly use parking spaces that are left vacant by workers/patients who already have left earlier.

${ }^{7}$ So, for the marginal parking space, the sum of the (inverse) parking demand functions for each day of the week must equal the weekly parking costs.

${ }^{8}$ Given identical demand functions on peak days, the peak day parking price is equal to the weekly fixed costs divided by the number of peak days.
} 


\section{The data}

We focus on a middle-sized hospital in The Hague, called Bronovo, which is in a neighbourhood with residential parking permit only, so workers who commute by car (have to) rely on employerprovided parking. The data used in the empirical analysis combines information from the hospital's daily parking lot use, daily working hours schedules for a period of one and half year (1 April 20079 October 2008) and the personnel file at the end of the period (this file includes workers who have left). We observe the exact times of the workers' presence and parking use. Depending on the shift, a worker may work during the day or at night. Daytime workers, who normally enter between 7-9 am and exit between 4-5 pm, are subject to variation in the parking price. Night workers park for free. We distinguish between a period before and a period after 1 April 2008.

The number of daytime workers present on the hospital's premises varies over the days of the week as shown in Table $1 .{ }^{9}$ For example, there are, on average, 287 daytime workers present on Fridays and 361 on Tuesdays. These numbers underestimate peak employment because they exclude nightshift workers who are on the premises during a part of the day. Peak employment varies - on average - from a minimum of about 352 persons on Fridays to a maximum of about 407 persons on Mondays.

The variation in (peak) employment induces a variation in the demand for (peak) parking space over the week. ${ }^{10}$ As can be seen from Table 1, Monday, Tuesday and Thursday are peak days, while Wednesday and Friday are slack days. For example, on Tuesdays, parking demand is on average 275 , about 40 places higher than on Fridays (so, by about $20 \%$ ). ${ }^{11}$

The hospital provides 676 parking spaces, of which 120 are reserved for workers, 220 for both workers and patients/visitors, 316 for patients/visitors and 20 for people with a physical

\footnotetext{
${ }^{9}$ For the descriptives, we discuss data provided for the period before 1 April 2008. The descriptives are similar after 1 April 2008.

${ }^{10}$ The patients' presence covaries with the workers' presence. Hence, fluctuations in overall demand for hospital parking by workers and patients are the result of within-week employment fluctuations.

${ }^{11}$ These figures exclude parking used by 50 medical doctors who park for free and who are not included in the administrative data available to us.
} 
handicap, so there are maximally 330 parking spaces available to workers ${ }^{12}$, a number which exceeds the workers' average peak demand. Hence, workers' demand is never constrained because they tend to arrive before patients and visitors (furthermore there is hardly any excess demand for parking by patients and visitors at the hospital during the period examined).

We exclude observations for workers who always or never park, during the period of observation (as the effect of the parking price is not identified for this sample of workers). Our sample amounts then to 132,292 employment days by 784 workers over 384 workdays. The average daily parking probability of these workers is $60 \%$. The average workers' commuting distance is 16 $\mathrm{km}$. Their average age is 37 years; $56 \%$ work full-time and $93 \%$ have a permanent contract.

Table 1: Average Number of Workers, Parking Places and Prices.

\begin{tabular}{lcc|cc|c|cc|cc|c}
\hline \multicolumn{5}{c}{ Before 1 April 2008 } & \multicolumn{3}{c}{ After 1 April 2008 } \\
\hline & Workers present & $\begin{array}{c}\text { Parking places } \\
\text { occupied }\end{array}$ & $\begin{array}{c}\text { Parking } \\
\text { price }\end{array}$ & Workers present & $\begin{array}{c}\text { Parking places } \\
\text { occupied }\end{array}$ & $\begin{array}{c}\text { Parking } \\
\text { price }\end{array}$ \\
\hline & Daytime & Peak & Daytime Peak & & Daytime & Peak & Daytime Peak & \\
\hline Monday & 339 & 407 & 224 & 254 & 2.65 & 336 & 406 & 214 & 256 & 1.50 \\
Tuesday & 361 & 421 & 234 & 264 & 2.66 & 355 & 417 & 233 & 275 & 1.49 \\
Wednesday & 320 & 384 & 202 & 233 & 2.65 & 315 & 378 & 206 & 247 & 0 \\
Thursday & 341 & 404 & 224 & 253 & 2.66 & 334 & 399 & 217 & 258 & 1.48 \\
Friday & 287 & 352 & 196 & 226 & 2.66 & 286 & 352 & 194 & 234 & 0 \\
\hline
\end{tabular}

Note: Parking by 50 medical doctors is excluded. "Daytime" refers to daytime workers only. "Peak" denotes the maximum number on a day.

Before 1 April 2008, the daily parking price depended on the employee's commuting distance and was a combination of a parking fee and a foregone bonus for not parking. Workers received a bonus of $€ 0.20$ per kilometre for not parking (up to a maximum $€ 2$ ). In addition, workers had to pay $€ 1.10$, $€ 1$, or $€ 0.80$ for parking when the commute was less than 10,10 to 20 or more

\footnotetext{
${ }^{12}$ Staff may use other parking places but then they pay the same price as other users.
} 
than $20 \mathrm{~km}$, respectively. So, the effective parking price varied from $€ 1.10$ to $€ 2.80 .{ }^{13}$ After 1 April 2008, the price also varied per day of the week: on peak days (Mondays, Tuesdays, and Thursdays), workers within 5 , from 5 to 10 , or further than $10 \mathrm{~km}$ from the hospital, paid $€ 3$, $€ 2$, or $€ 1$, respectively. On the other days, parking was free.

The change in parking policy on 1 April 2008 resulted, on average, into a price increase of one euro for workers within the $5 \mathrm{~km}$ radius, a negligible change for workers between 5 and $10 \mathrm{~km}$ and a price decrease of $€ 1.80$ for workers further than $10 \mathrm{~km}$ from the hospital. ${ }^{14}$ The change in policy induced a decrease in the average parking price paid of about $€ 1.20$ on peak days and $€ 2.65$ on slack days. The reduction in the average price, although rather small compared to the overall cost of driving to work (gasoline, wear and tear), is consistent with the aggregate data that suggest a (small) increase in parking use, particularly on slack days (see Table 1).

Figure 1: Changes in Parking Price and Parking Propensity.

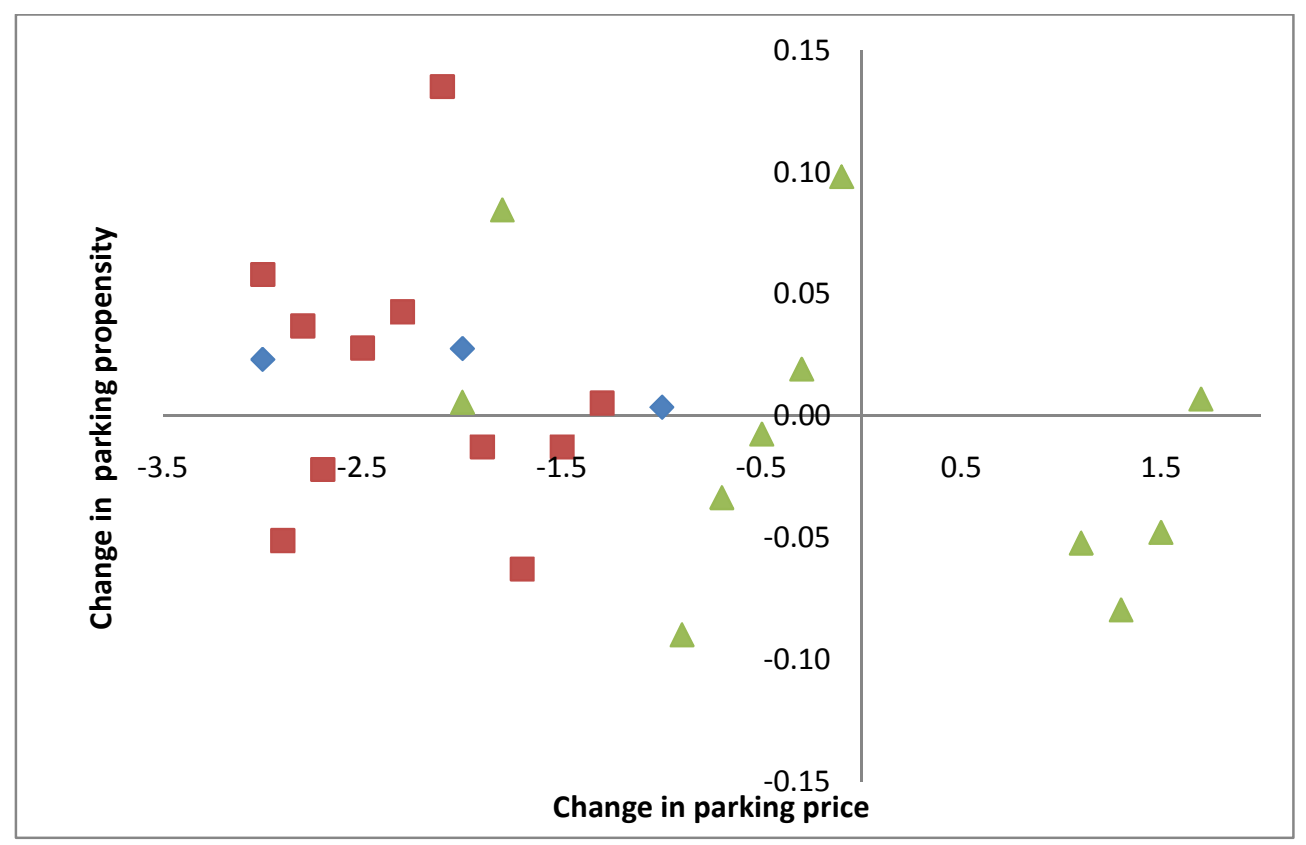

Note: $\boldsymbol{\Delta}$ refers to strategy A; $\mathbf{\square}$ refers to strategy B; $\diamond$ refers to strategy C.

\footnotetext{
${ }^{13}$ For example, a worker at $4 \mathrm{~km}$ who parked the car would forego a bonus equal to $€ 0.80$ and pay a parking fee of $€ 1.10$, so the effective parking price is $€ 1.90$.

${ }^{14}$ About $9 \%$ of car parkers have a commuting distance of less than $5 \mathrm{~km}$, whereas $61 \%$ have a distance that exceeds $10 \mathrm{~km}$.
} 
The combination of (i) a change in pricing regime on 1 April 2008, (ii) differences in parking prices between peak and slack days (after 1 April 2008) and (iii) a price that varies with the workers' commuting distance results in 25 differences in the parking price (faced by the same worker). We use a difference-in-differences methodology to estimate the effect of the parking price on demand that exploits these differences. We have categorised these 25 differences in three types of "strategies", which makes it possible to identify the effect of the change in parking price in different ways.

The first strategy, A, uses (within-worker) price variation between peak days. The second strategy, B, exploits the same type of variation, but only on slack days. The third strategy, C, uses (within-worker) price variation between different days of the week after 1 April 2008. We emphasise that these three strategies are mutually exclusive, so they rely on different sources of variation in the data. Figure 1 shows the relationship between changes in the price and in the average parking propensity. It is clearly negative for all three identification strategies.

\section{Empirical analysis}

The essence of the paper lies in the estimation of the daily demand function. Our dependent variable is whether a (dayshift) worker makes use of hospital parking on a given day of employment. We use the three identification strategies described above. We also combine these strategies to obtain more precise estimates. We estimate linear probability models that include worker-specific and dayspecific fixed effects. In this way, we avoid bias in estimates related to time-invariant unobserved worker heterogeneity (e.g., workers' preferences for car use; household income) as well as unobserved day heterogeneity (e.g., the weather ${ }^{15}$ ). Given these fixed effects, the effects of variables that vary across workers and day of employment can be identified. We are able to identify

${ }^{15}$ For many Dutch hospital workers, biking is the main alternative to driving, which can be a rather unpleasant experience in bad weather, so parking demand is sensitive to weather. 
the effects of the daily parking price, workhours at the hospital, number of work activities (i.e., tending patients, and pharmacy) and whether the worker also worked off the hospital premises (e.g. visiting patients at home). Descriptive statistics for these variables are presented in the Appendix. They show for example that most hospital workers (78\%) work exactly 8 hours on a day and almost all workers $(97 \%)$ do not leave the hospital's premises.

The empirical results are presented in Table 2. Our main result is that for each strategy the parking price has a (statistically significant) negative effect on the probability to park of approximately -0.015 . The estimated effects are (almost) identical for each identification strategy, which increases confidence in the estimation procedure. Combining the strategies, the estimated effect is -0.015 with a standard error of $0.002 .^{16}$

We have examined alternative specifications using the combined strategy. For example, we have estimated models adding the square of parking price. Although its coefficient is (just) statistically significant, the marginal effects are $-0.010,-0.014$, and -0.013 when the price is one, two or three euro, respectively, so the marginal effect is, more or less, constant over the relevant range. We have also interacted the price with three distance dummies (up to $10 \mathrm{~km}, 10$ to $20 \mathrm{~km}$, and more than $20 \mathrm{~km}$ ). The effect of price is then $-0.007,-0.016$ and -0.017 respectively. ${ }^{17}$ This result is slightly surprising as one would expect that the effect would become weaker with distance, which we do not find. We have also re-estimated the models for specific subsamples. For example, we have excluded workers hired after certain dates (e.g. 1 February 2008) and workers who have left the hospital before certain dates (e.g. 1 June 2008), but the results remain the same. Finally, we have estimated a conditional logit model instead of a linear probability model. For computational

\footnotetext{
${ }^{16}$ The results for the control variables make sense. Workers with off-site work activities have a higher probability to park. The number of hours at work has a positive effect on the probability to park, which is consistent with the idea that given a fixed daily parking price, the hourly parking price is decreasing in the number of hours worked. Since we use worker and day fixed effects, we believe these effects can be interpreted as causal. Interestingly, this is the first study that is able to demonstrate the causal effect of labour supply on car parking (and therefore car use). Only $8 \%$ of the predicted probability to park falls outside the 0 to 1 interval.

${ }^{17}$ The hypothesis of a constant marginal effect is rejected at the $5 \%$ confidence level $(\mathrm{F}=3.76$ with $\mathrm{p}$-value of 0.001 ).
} 
reasons, we restricted the analysis to strategy $\mathrm{C}$ (which uses less observations and less fixed effects) as it takes even for this strategy several days to estimate a conditional logit model. We found almost identical results.

Table 2: Linear Probability Estimates of Parking Probability

\begin{tabular}{lc|c|c|c}
\hline & Strategy A & Strategy B & Strategy C & All strategies \\
& & & & \\
\hline Price (in $€$ per day) & -0.014 & -0.014 & -0.016 & -0.015 \\
Activity off-site & $(0.003)$ & $(0.007)$ & $(0.006)$ & $(0.002)$ \\
& 0.050 & 0.011 & 0.109 & 0.038 \\
Working hours & $(0.014)$ & $(0.020)$ & $(0.022)$ & $(0.012)$ \\
Four & & & & \\
& 0.167 & 0.190 & 0.167 & 0.168 \\
Five & $(0.014)$ & $(0.018)$ & $(0.020)$ & $(0.011)$ \\
& 0.137 & 0.252 & 0.216 & 0.179 \\
Six & $(0.014)$ & $(0.019)$ & $(0.022)$ & $(0.011)$ \\
& 0.203 & 0.250 & 0.238 & 0.219 \\
Seven & $(0.014)$ & $(0.019)$ & $(0.021)$ & $(0.011)$ \\
& 0.007 & 0.005 & -0.065 & 0.003 \\
Eight & $(0.012)$ & $(0.016)$ & $(0.019)$ & $(0.009)$ \\
& 0.207 & 0.266 & 0.247 & 0.227 \\
Nine or more & $(0.011)$ & $(0.014)$ & $(0.016)$ & $(0.008)$ \\
\multirow{2}{*}{ Activities } & 0.228 & 0.283 & 0.275 & 0.242 \\
One & $(0.012)$ & $(0.017)$ & $(0.018)$ & $(0.009)$ \\
& & & & \\
Two & 0.035 & 0.126 & 0.030 & 0.062 \\
& $(0.029)$ & $(0.048)$ & $(0.039)$ & $(0.025)$ \\
& 0.018 & 0.133 & 0.049 & 0.054 \\
No. of observations & $(0.025)$ & $(0.043)$ & $(0.032)$ & $(0.021)$ \\
No. of workers & 82,789 & 49,503 & 39,141 & 132,292 \\
\hline Note. stan & 784 & 784 & 631 & 784 \\
\hline
\end{tabular}

Note: standard errors in parentheses. The three strategies are explained in the main text.

One interesting feature of the linear probability model (e.g. compared to the conditional logit model) is that worker (and day) fixed effects are identified. The worker fixed effects are consistently estimated in our application because the time dimension of the panel is large (Wooldridge 2002), which offers the possibility to apply a two-stage estimation procedure. We use the worker fixed effects obtained from the estimates presented in Table 2 in a second stage, by regressing them on time-invariant worker characteristics (age, wage, part-time job, temporary job, 
$\log$ of commuting distance). ${ }^{18} \mathrm{We}$ find that the probability to park increases strongly with distance and is slightly higher for part-time and temporary workers. The $\mathrm{R}^{2}$ of the second stage regression is rather low (0.16) implying that most of the time-invariant heterogeneity is unexplained. This suggests that the use of worker fixed effect to obtain consistent results for estimates such as reported in Table 2 are essential. This is confirmed by re-estimating the linear probability model without worker fixed effects (but with time-invariant worker characteristics). We now find that price has a positive (rather than a negative) effect on parking, which is clearly a spurious result due to a lack of relevant time-invariant control variables.

\section{Deadweight loss}

To estimate the deadweight loss of non-optimal pricing, we use a resource cost of $€ 24$ per week (about $€ 1,200$ per year). ${ }^{19}$ Recall that according to theory, the hospital must vary the optimal price per day and set the price such that on peak days demand equals supply. On slack days, the price must be set to zero. For the hospital, we observe three peak days, so the optimal price is $€ 8$ on these days. The difference between the actual and the optimal price is the 'parking subsidy'.

According to classical welfare economics, the use of a linear parking demand function on a sample of workers present at the hospital implies that the daily deadweight loss per worker present is equal to (the absolute value of) 0.5 times the effect of price on demand (-0.015) times the square of the parking subsidy. This calculation is usually called the 'rule of half' (e.g., Varian, 1992), and ignores the welfare effects of nonoptimal pricing through additional congestion. ${ }^{20}$

\footnotetext{
${ }^{18}$ Strictly speaking, these characteristics are not time-invariant, but they are invariant in our application because they are measured at one point in time. As time variation in these characteristics is small, this has little consequence for the estimates.

${ }^{19}$ We have calculated this cost using two approaches that generate about the same value. Over the period considered, the parking price for patients and visitors on weekdays was $€ 1.50$ per hour (currently it is $€ 2.50$ ) up to a maximum of $€ 7.00$ per day. This suggests that the weekly fixed costs are around $€ 35$. The cost of adding space using a multi-story parking lot are estimated by parking engineers to be $€ 20$ to $€ 30$ per week. We use $€ 24$, which is a conservative estimate of the cost.

${ }^{20}$ This rule assumes that parking is not an input in the production function (Katz and Mankiw, 1985), which is a reasonable assumption, because hardly any worker works offsite. It also assumes that there is no excess demand, which is a reasonable assumption for workers. Excess supply of parking to workers on slack days
} 
When hospitals offer parking for free, as is the case for about two thirds of Dutch hospitals, the parking subsidy is $€ 8$ on peak days (and $€ 0$ on slack days). The annual deadweight loss for hospitals amounts then to $€ 74.88$ per worker present $\left(52 \times 0.5 \times 0.015 \times 3 \times 8^{2}\right)$, which is equivalent to $€ 126$ per parking place, about $10.5 \%$ of the annual resource cost. ${ }^{21}$

Given the additional assumption that workers who do not park at the hospital premises do not travel by car, then the average increase in external commuting costs due to the increase in congestion induced by free parking is on peak days about $€ 0.30$ per worker (the average one-way commuting distance is $16 \mathrm{~km}$, so it is calculated as $0.015 * 8 * 2 * 16 \mathrm{~km} * € 0.08 / \mathrm{km}$, using an external costs of $€ 0.08 / \mathrm{km}$ provided by Small and Verhoef, 2007), so the annual loss due to increased congestion is about $€ 36$ per worker, roughly $50 \%$ of the private deadweight loss. Hence, our estimates of the deadweight loss for hospitals are rather conservative and underestimates of the economy-wide welfare loss.

We now focus on the case that hospitals use a fixed price per day (the same price on all days of the week), which holds for about one third of the Dutch hospitals. The deadweight loss of nonoptimal pricing depends on the level of the price. We use the fixed price that minimises the deadweight loss, which can be shown to be the mean daily cost (€4.80 in our data). The total loss is then the sum of the losses on peak days (due to excess demand) and the losses on slack days (due to excess supply). The annual loss is then $€ 30$ per worker $\left(52 \times 0.5 \times 0.015 \times\left(3 \times 3.20^{2}+2 \times 4.80^{2}\right)\right)$, so $€ 50.55$ per parking space. Thus, the minimum loss of using a fixed price is $4.21 \%$ of the resource costs. This is a substantial loss, but less than half of the loss when parking is free.

Dutch hospitals that use a fixed price usually charge a parking price of $€ 1.00$ or $€ 1.50$ per day. Using the latter, the corresponding annual loss is $€ 86.39$ per parking space, so $7.20 \%$ of the resource cost. Although a welfare improvement compared to free parking, this loss is much higher

may prevent excess demand by patients/visitors, but during the period examined, there was no excess demand.

${ }^{21}$ To calculate the loss per parking place, we divide the loss per worker by the average parking propensity, which is 0.60 . 
than using the mean price (of €4.80). Reducing the price on slack days does not have much effect on welfare. For example, when hospitals charge workers $€ 1.50$ per day on peak days and zero on slack days, then the annual loss is $6.95 \%$ of the resource cost, which is only slightly less than the loss of charging a fixed price of $€ 1.50$. The zero price on slack days decreases workers' overall parking expenditure by almost $40 \%$, which makes a policy that introduces paid parking for workers more acceptable to workers and their representatives.

These estimates are useful to derive aggregate welfare losses. In the Netherlands, we estimate that there are about 140,000 parking places for hospital workers. For convenience, we assume that all places cost $€ 1200$ per year. About two-third of hospitals do not charge and assuming that the other hospitals charge $€ 1.50$ per day, the total annual loss for the Dutch hospital sector is in the order of $€ 16$ million $((0.67 x € 126+0.33 x € 86) \times 140,000)$, about $9.4 \%$ of the resource costs. Although our estimates may be regarded as only indicative (as our estimates are based on one hospital), this estimate seems a useful indicator of the order of magnitude of the aggregate loss. This loss excludes any additional losses to the economy because of increased congestion.

A share of this loss is likely induced by a distortionary tax regime, which prevails in the Netherlands and all other countries we are aware of. The presence of a positive income tax rate together with a fiscal regime that does not consider free parking as a benefit in kind induce firms to offer free parking and to increase parking supply. The marginal income tax for Dutch workers with annual earnings in excess of $€ 20.000$ is about $50 \%$. Optimal fringe benefits taxation, viz. a tax that maximises welfare in the economy, implies that the difference between the firms' cost of providing a benefit and the price paid by the worker for this benefit must be taxed as income (so, the worker pays for the full price of the benefit out of net wages).

To determine the distortionary effect of current tax policies regarding hospital parking, it is important to realise that, in principle, hospitals may reduce gross wages for employees who park for free (see Katz and Mankiw, 1985). The tax-induced welfare loss is then 'only' one quarter of the loss induced by free parking, thus $€ 31$ per parking space, $2.6 \%$ of resource costs. However, 
hospitals never differentiate wages based on workers' parking use, so the tax-induced deadweight loss must be substantially higher.

\section{Conclusion}

We have studied the workers' demand for hospital parking. We identified the price effect on parking demand using a difference-in-differences methodology for a Dutch hospital. The loss generated by non-optimal pricing of parking in the hospital sector is about $9 \%$ of the hospitals' parking resource costs. This excludes additional costs of congestion induced by on the pricing of parking that may be up to half of the hospital sector deadweight losses. It is shown that by using peak pricing on high demand days, this loss can be strongly reduced. It is plausible that a (substantial) proportion of this loss arises from a distortionary tax rule that does not tax free employer-paid parking as a fringe benefit in kind. Free parking for hospital workers is frequently proposed in the UK press as a useful mandatory government policy. Our results (in line with intuition) suggest that this is not such a good idea from a welfare perspective. 


\section{Reference List}

Arnott, R., A. De Palma and R. Lindsey (1991), A temporal and spatial equilibrium analysis of commuter parking, Journal of Public Economics, 45, 301-335

Katz A., Mankiw G. (1985) “How Should Fringe Benefits Be Taxed?” National Tax Journal, 38, (March), 37-46.

National Parking Association (2009) Parking in America: The second annual review of parking rates in North America. National Parking Association, Washington DC.

Noether, M. (1988) “Competition among hospitals” Journal of Health Economics, 7, 259-284.

Parking Consultants Ltd. (2010) http://www.parkingconsultantsltd.com/11n.htm.

Pigou A.C. (1912) Wealth and Welfare, Macmillan Company, New York.

Small K.A., Verhoef E.T. (2007) The Economics of Urban Transportation, Routledge, New York.

Shoup, D.C. (2005), The High Cost of Free Parking, Planners Press, Chicago

Thomson, R.B. (1994) “Competition among hospitals in the United States” Health Policy, 27, 205231.

Varian H.R. (1992) Microeconomic Analysis, Norton, New York.

Wooldridge J.M. (2002) Econometric Analysis of Cross Section and Panel Data, MIT Press, Cambridge. 


\section{Appendix: Descriptives}

Table A1: Descriptive Statistics

\begin{tabular}{lcc}
\hline Variable & Mean & Standard deviation \\
\hline Parking price $(€)$ & 2.070 & 1.024 \\
Activity off-site & 0.032 & 0.176 \\
Daily working hours & & \\
Three or less & 0.017 & 0.129 \\
Four & 0.036 & 0.186 \\
Five & 0.033 & 0.179 \\
Six & 0.026 & 0.160 \\
Seven & 0.042 & 0.200 \\
Eight & 0.777 & 0.416 \\
Nine or more & 0.069 & 0.253 \\
Number of Activities & & \\
One & 0.957 & 0.202 \\
Two & 0.040 & 0.197 \\
Three & 0.003 & 0.049 \\
\hline No. of observations & 132,292 &
\end{tabular}

